\title{
Multiphase chemistry experiment in Fogs and Aerosols in the North China Plain (McFAN): integrated analysis and intensive winter campaign $2018 \dagger$
}

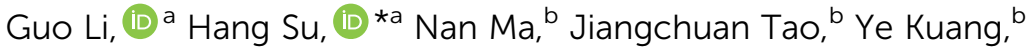 \\ Qiaoqiao Wang, ${ }^{\mathrm{b}}$ Juan Hong, ${ }^{\mathrm{b}}$ Yuxuan Zhang, ${ }^{\mathrm{C}}$ Uwe Kuhn, ${ }^{\mathrm{a}}$ \\ Shaobin Zhang, ${ }^{\mathrm{b}}$ Xihao Pan, ${ }^{\mathrm{a}}$ Nan Lu, ${ }^{\mathrm{b}}$ Min Tang, ${ }^{\mathrm{b}}$ Guangjie Zheng, (D) a \\ Zhibin Wang, ${ }^{d}$ Yang Gao, ${ }^{e}$ Peng Cheng, ${ }^{f}$ Wanyun $\mathrm{Xu},{ }^{\mathrm{g}}$ \\ Guangsheng Zhou, ${ }^{\mathrm{h}}$ Chunsheng Zhao, ${ }^{\mathrm{i}}$ Bin Yuan, ${ }^{\mathrm{b}}$ Min Shao, \\ Aijun Ding, ${ }^{\mathrm{C}}$ Qiang Zhang, ${ }^{\mathrm{j}}$ Pingqing Fu, (D) ${ }^{\mathrm{k}}$ Yele Sun, (D)' \\ Ulrich Pöschl (iD a and Yafang Cheng iD a
}

Received 6th August 2020, Accepted 5th October 2020

DOI: $10.1039 /$ dOfd00099j

Fine-particle pollution associated with winter haze threatens the health of more than 400 million people in the North China Plain. The Multiphase chemistry experiment in Fogs and Aerosols in the North China Plain (McFAN) investigated the physicochemical mechanisms leading to haze formation with a focus on the contributions of multiphase processes in aerosols and fogs. We integrated observations on multiple platforms with regional and

\footnotetext{
${ }^{a}$ Max Planck Institute for Chemistry, Mainz, 55128, Germany. E-mail: h.su@mpic.de ${ }^{b}$ Institute for Environmental and Climate Research (ECI), Jinan University, Guangzhou, 511443, China ${ }^{c}$ School of Atmospheric Sciences, Nanjing University, Nanjing, 210023, China

${ }^{d}$ Research Center for Air Pollution and Health, College of Environmental and Resource Sciences, Zhejiang University, Hangzhou, China

${ }^{e}$ Key Laboratory of Marine Environment and Ecology, Ministry of Education, Institute for Advanced Ocean Study, Ocean University of China, Qingdao, 266100, China

Institute of Mass Spectrometry and Atmospheric Environment, Jinan University, Guangzhou, 511443, China ${ }^{g}$ State Key Laboratory of Severe Weather, Key Laboratory for Atmospheric Chemistry, Institute of Atmospheric Composition and Environmental Meteorology, Chinese Academy of Meteorological Sciences, Beijing, 100081, China

${ }^{h}$ Gucheng Experimental Station of Ecological and Agricultural Meteorology, Chinese Academy of Meteorological Sciences, Beijing, 100081, China

${ }^{i}$ Department of Atmospheric and Oceanic Sciences, School of Physics, Peking University, Beijing, China ${ }^{j}$ Ministry of Education Key Laboratory for Earth System Modeling, Department of Earth System Science, Tsinghua University, Beijing 100084, China

${ }^{k}$ Institute of Surface-Earth System Science, Tianjin University, Tianjin, 300072, China

${ }^{I}$ State Key Laboratory of Atmospheric Boundary Layer Physics and Atmospheric Chemistry, Institute of Atmospheric Physics, Chinese Academy of Sciences, Beijing, China

$\dagger$ Electronic supplementary information (ESI) available. See DOI: 10.1039/d0fd00099j
} 
box model simulations to identify and characterize the key oxidation processes producing sulfate, nitrate and secondary organic aerosols. An outdoor twin-chamber system was deployed to conduct kinetic experiments under real atmospheric conditions in comparison to literature kinetic data from laboratory studies. The experiments were spanning multiple years since 2017 and an intensive field campaign was performed in the winter of 2018. The location of the site minimizes fast transition between clean and polluted air masses, and regimes representative for the North China Plain were observed at the measurement location in Gucheng near Beijing. The consecutive multiyear experiments document recent trends of $\mathrm{PM}_{2.5}$ pollution and corresponding changes of aerosol physical and chemical properties, enabling in-depth investigations of established and newly proposed chemical mechanisms of haze formation. This study is mainly focusing on the data obtained from the winter campaign 2018. To investigate multiphase chemistry, the results are presented and discussed by means of three characteristic cases: low humidity, high humidity and fog. We find a strong relative humidity dependence of aerosol chemical compositions, suggesting an important role of multiphase chemistry. Compared with the low humidity period, both $\mathrm{PM}_{1}$ and $\mathrm{PM}_{2.5}$ show higher mass fraction of secondary inorganic aerosols (SIA, mainly as nitrate, sulfate and ammonium) and secondary organic aerosols (SOA) during high humidity and fog episodes. The changes in aerosol composition further influence aerosol physical properties, e.g., with higher aerosol hygroscopicity parameter $\kappa$ and single scattering albedo SSA under high humidity and fog cases. The campaign-averaged aerosol pH is $5.1 \pm 0.9$, of which the variation is mainly driven by the aerosol water content (AWC) concentrations. Overall, the MCFAN experiment provides new evidence of the key role of multiphase reactions in regulating aerosol chemical composition and physical properties in polluted regions.

\section{Introduction}

In the recent decade, frequently occurring severe haze events in the North China Plain (NCP) have triggered numerous studies on the underlying formation mechanisms, and the contribution of multiphase chemistry to haze formation has become one of the focal points. ${ }^{1-4}$ Besides directly emitted primary pollutants ${ }^{5,6}$ high levels of secondary inorganic aerosols (SIA, mainly sulfate, nitrate and ammonium) and secondary organic aerosols (SOA) have been observed during haze episodes in many regions of China. As an important component of fine particles, sulfate shows rapid formation during haze events and this high growth rate could not be explained by current state-of-the-art models, suggesting the existence of yet unknown sources of sulfate. ${ }^{2}$ Cheng et al. ${ }^{1}$ discovered that high rates of sulfate production and large differences between observed and modeled sulfate concentrations were related to high aerosol water content (AWC), suggesting that aqueous-phase oxidation in aerosol water may play a key role, following different reaction pathways depending on aerosol $\mathrm{pH}$ and oxidant concentration levels: at $\mathrm{pH}>4.5$ multiphase reactions of $\mathrm{NO}_{2}$ and $\mathrm{O}_{3}$ dominate, while at $\mathrm{pH}<4.5$ reactions involving transition metal ions (TMI) and $\mathrm{H}_{2} \mathrm{O}_{2}$ may prevail. ${ }^{1}$ Though the importance of multiphase reactions has been widely accepted, the exact formation pathway is still under debate. ${ }^{1,2,7-16}$ Besides sulfate, nitrate, ammonium and secondary organic aerosols also show distinct 
characteristics during the haze events, and the increased contribution of multiphase reactions has been suggested as a potential explanation.

To elucidate the chemical mechanisms leading to severe haze formation in Beijing and the NCP, a number of field campaigns and laboratory studies have been carried out. These early studies have revealed several challenges. For example, the observed aerosol concentrations in Beijing were found to be strongly influenced by atmospheric transport processes, which may challenge proper analysis of the prevailing chemical reactions. ${ }^{2}$ Likewise, simple laboratory experiments may differ from that in the real atmosphere, in which synergic effects or high ionic strengths may lead to orders of magnitude difference in reaction rates. Besides, many studies lack information about aerosol $\mathrm{pH}$, which controls the rates of many atmospheric multiphase reactions. ${ }^{1}$

Under this background, the Multiphase chemistry experiment in Fogs and Aerosols in the North China Plain (McFAN) was organized to advance our understanding of the physical-chemical mechanisms leading to severe haze formation, especially with a focus on the contributions of multiphase processes in aerosols and fogs. Instead of Beijing, we selected a site located in the central polluted region of the NCP, where the influence of transport was smaller. We made a comprehensive design to cover more parameters (such as aerosol $\mathrm{pH}$ ) that are required for a closure study on the multiphase reactions. We also introduced an environmental chamber system and an automatic-shifting aerosol inlet system to perform kinetic experiments under real ambient air conditions. In this overview paper, the field site and the instrumentation deployed during the McFAN experiment are firstly described. Then new observation-based findings are presented.

\section{Experiment design and criteria for site selection}

One of the main scientific objectives of the McFAN experiment was to investigate the effects of multiphase processes on particle formation and evolution. To achieve this goal, the related research was schemed into three cases: (1) the formation and evolution of aerosols during fog conditions (i.e., fog case); (2) the formation and transformation of aerosols during high relative humidity days and the respective impact of multiphase reactions (i.e., high $\mathrm{RH}$ case); (3) the formation and transformation of aerosols during low humidity days (i.e. low RH case). Given the temporal and spatial variations of the air quality in the NCP, one intensive field campaign was performed from $11^{\text {th }}$ November to $24^{\text {th }}$ December 2018 at the Gucheng site, to capture fog and haze events. The observation was equipped with abundant online and offline instruments, allowing to record and analyze meteorological parameters as well as variations and properties of aerosol and gas species. The instruments and their measured parameters are listed in Table 1. Briefly, the trace gas instruments $\left(\mathrm{O}_{3}, \mathrm{NO}_{x}, \mathrm{CO}, \mathrm{SO}_{2}, \mathrm{NH}_{3}\right)$ from Chinese Academy of Meteorological Sciences (CAMS, see Table 1) were housed in an airconditioned room in a two-story building in the southern part of the Gucheng station, ${ }^{17}$ and the other instruments were installed in two air-conditioned containers placed on the north side of the site. To investigate multiphase reaction kinetics, an environmental chamber system was also employed. The 
Table 1 Instrumentation, measurement parameters, and partners involved in the McFAN experiment

\begin{tabular}{|c|c|c|c|}
\hline & Instrument & Measured parameter & Organization $^{a}$ \\
\hline \multirow[t]{16}{*}{ Aerosols } & Scanning Mobility Particle Sizer (SMPS) & $\begin{array}{l}\text { Aerosol number size } \\
\text { distribution (10-1000 } \\
\mathrm{nm})\end{array}$ & JNU \\
\hline & Aerodynamic Particle Sizer (APS) & $\begin{array}{l}\text { Aerosol number size } \\
\text { distribution }(0.5-20 \\
\mu \mathrm{m})\end{array}$ & JNU \\
\hline & Particle Size Magnifier (PSM) & $\begin{array}{l}\text { Aerosol number } \\
\text { concentration }(1-4 \mathrm{~nm})\end{array}$ & MPIC \\
\hline & Nephelometer & $\begin{array}{l}\text { Aerosol optical } \\
\text { properties }\end{array}$ & PKU \\
\hline & Aethalometer AE33 & $\begin{array}{l}\text { Black carbon optical } \\
\text { properties }\end{array}$ & JNU \\
\hline & Aerosol photometer & $\begin{array}{l}\text { Aerosol optical } \\
\text { properties }\end{array}$ & JNU \\
\hline & $\begin{array}{l}\text { Capture Vaporizer Time-of-Flight } \\
\text { Aerosol Chemical Speciation Monitor } \\
\text { (CV-ToF-ACSM) }\end{array}$ & Aerosol composition & NJU, IAP-CAS \\
\hline & OC/EC Aerosol Analyzer & Aerosol composition & JNU \\
\hline & $\begin{array}{l}\text { Four-channel high-volume aerosol } \\
\text { sampler }\end{array}$ & Aerosol composition & JNU \\
\hline & Cascade impactor & Aerosol composition & CAMS \\
\hline & $\begin{array}{l}\text { Cloud Condensation Nucleus Counter } \\
\text { (CCNC) }\end{array}$ & $\begin{array}{l}\text { Aerosol hygroscopicity } \\
\text { (combined with DMA) }\end{array}$ & JNU \\
\hline & $\begin{array}{l}\text { Hygroscopic Tandem Differential } \\
\text { Mobility Analyzer (HTDMA) }\end{array}$ & Aerosol hygroscopicity & JNU \\
\hline & Humidified nephelometer & Aerosol hygroscopicity & PKU \\
\hline & Single-Particle soot Photometer (SP2) & Black carbon & JNU \\
\hline & $\begin{array}{l}\text { Centrifugal Particle Mass Analyzer } \\
\text { (CPMA) }\end{array}$ & $\begin{array}{l}\text { Black carbon density } \\
\text { (combined with SP2) }\end{array}$ & JNU \\
\hline & $\begin{array}{l}\text { Ground-based Counterflow Virtual } \\
\text { Impactor (GCVI) }\end{array}$ & Fog & JNU \\
\hline \multirow[t]{9}{*}{ Trace gases } & $\begin{array}{l}\text { Proton-Transfer-Reaction Mass } \\
\text { Spectrometry (PTR-MS) }\end{array}$ & VOCs & JNU \\
\hline & $\begin{array}{l}\text { Chemical Ionization Mass } \\
\text { Spectrometry (CIMS) }\end{array}$ & VOCs & JNU \\
\hline & Model $43 \mathrm{i} \mathrm{SO}_{2}$ analyzer & $\mathrm{SO}_{2}$ & MPIC, CAMS \\
\hline & Model $42 \mathrm{i} \mathrm{NO}_{x}$ analyzer & $\mathrm{NO}_{x}$ & MPIC, CAMS \\
\hline & Model $49 \mathrm{i} \mathrm{O}_{3}$ analyzer & $\mathrm{O}_{3}$ & MPIC, CAMS \\
\hline & $\begin{array}{l}\text { LOng Path Absorption Photometer } \\
\text { (LOPAP) }\end{array}$ & HONO & JNU \\
\hline & $\begin{array}{l}\text { Monitor for AeRosols and Gases in } \\
\text { ambient Air (MARGA) }\end{array}$ & $\begin{array}{l}\text { Trace gases: } \mathrm{HCl}, \mathrm{SO}_{2} \\
\mathrm{NH}_{3}, \mathrm{HNO}_{3}, \mathrm{HONO}\end{array}$ & JNU \\
\hline & $\begin{array}{l}\text { Picarro G2103 gas concentration } \\
\text { analyzer }\end{array}$ & $\mathrm{NH}_{3}$ & JNU \\
\hline & $\begin{array}{l}\text { Economical ammonia analyzer (LGR } \\
\text { DLT-100) }\end{array}$ & $\mathrm{NH}_{3}$ & CAMS \\
\hline
\end{tabular}


Table 1 (Contd.)

Multiphase Environmental chamber system reactions
Multiphase reaction MPIC

kinetics, sulfate

formation rate

${ }^{a}$ JNU: Jinan University; NJU: Nanjing University; PKU: Peking University; IAP-CAS: Institute of Atmospheric Physics Chinese Academy of Sciences; CAMS: Chinese Academy of Meteorological Sciences; MPIC: Max Planck Institute for Chemistry.

chambers were installed on the roof of one container and the associated analyzers were located inside the container. Data obtained from the chamber experiments are still under analysis, therefore are not presented in this study.

The Gucheng site was selected to carry out the McFAN campaign. The site is $\sim 100 \mathrm{~km}$ southwest of Beijing and $\sim 35 \mathrm{~km}$ north of Baoding city. It is a suburban site located at the Ecological and Agricultural Meteorology Station $\left(39^{\circ} 09^{\prime} \mathrm{N}\right.$, $115^{\circ} 44^{\prime} \mathrm{E}$ ) of the Chinese Academy of Meteorological Sciences. ${ }^{18}$ It is surrounded by agricultural fields (for cultivation of wheat and corn) and the closest residential town (Dingxing county) is $\sim 1.5 \mathrm{~km}$ away. The location of the site minimizes fast transition between clean and polluted air masses (e.g., in Beijing), and helps to maintain a pollution regime representative for the NCP, making it an ideal position to investigate atmospheric chemical processes.

\section{Overview of meteorology, gas and aerosol variation}

Fig. 1 shows the observed time series of meteorological parameters, concentrations of inorganic gas pollutants and $\mathrm{PM}_{2.5}$ during the McFAN campaign. The average wind speed observed over the whole campaign was only $\sim 0.5 \mathrm{~m} \mathrm{~s}^{-1}$, but occasionally it could reach up to $\sim 8.5 \mathrm{~m} \mathrm{~s}^{-1}$. For most of the measurement time, the wind speed displayed a diel variation with higher values during daytime than at nighttime. The level of ambient air relative humidity (RH) for the whole campaign can be generally classified into two stages: from $11^{\text {th }}$ November to $03^{\text {rd }}$ December, the daily averaged $\mathrm{RH}$ covered a high range of $45-89 \%$, deemed as high humidity period; from $04^{\text {th }}$ to $24^{\text {th }}$ December, the daily averaged $\mathrm{RH}$ was in a relatively low range of $23-69 \%$, considered as low humidity period. Moreover, two typical fog events (with $\mathrm{RH}=100 \%$ ) were observed during the campaign. All these periods are indicated by the colored rectangles in Fig. 1B. The ambient temperature $(T)$ ranged from $-14{ }^{\circ} \mathrm{C}$ to $18{ }^{\circ} \mathrm{C}$, with an average of $\sim 1.3{ }^{\circ} \mathrm{C}$. More information of the meteorological conditions can be found in the ESI. $\dagger$ The campaign-averaged concentrations of key gas pollutants were: $\sim 10 \mathrm{ppb}$ for $\mathrm{SO}_{2}$, $\sim 32 \mathrm{ppb}$ for $\mathrm{NO}_{2}, \sim 28 \mathrm{ppb}$ for $\mathrm{NH}_{3}$ and $\sim 7 \mathrm{ppb}$ for $\mathrm{O}_{3}$ (Fig. 1C and $\mathrm{D}$ ). The mass concentration of $\mathrm{PM}_{2.5}$ covered a wide range from $\sim 3$ to $\sim 462 \mu \mathrm{g} \mathrm{m}{ }^{-3}$ (Fig. 1E) with an average of $\sim 121 \mu \mathrm{g} \mathrm{m}^{-3}$. Additional information about volatile organic compounds (VOCs) can be found in Fig. S3.† Fig. 2 shows the variations of 

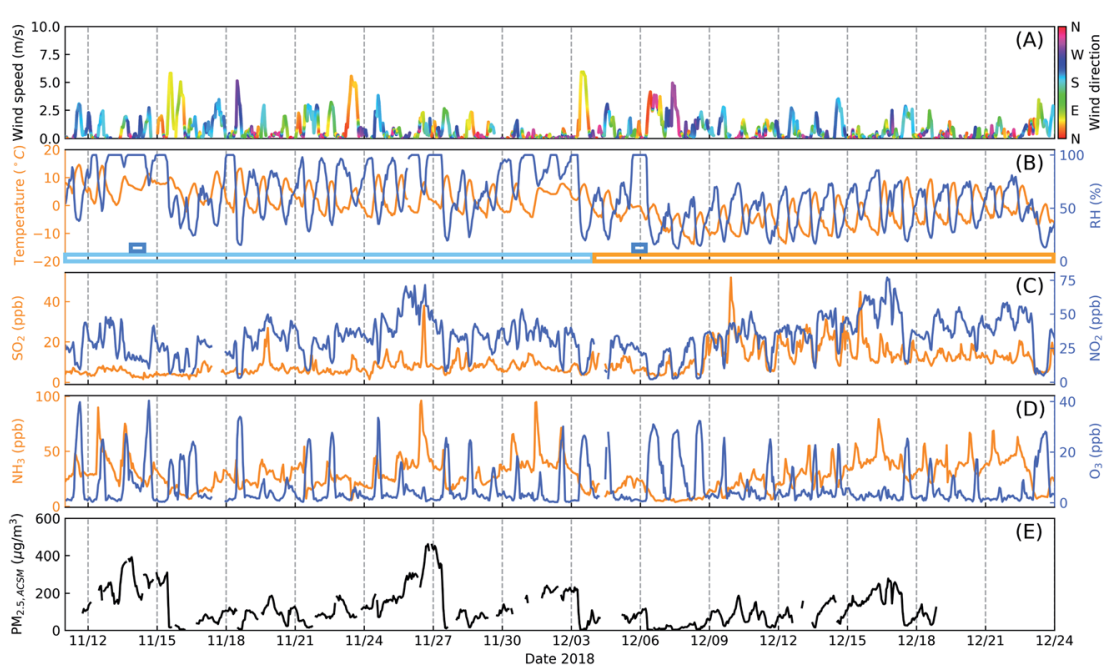

Fig. 1 Time series of meteorological parameters ( $A$ and $B$ ), inorganic gas pollutants ( $C$ and D) and mass concentration of $\mathrm{PM}_{2.5}$ (E) during the MCFAN campaign. The colored rectangles in panel (B) indicate different characteristic periods: dark blue - fog, light blue high humidity, orange - low humidity. The mass concentration of $\mathrm{PM}_{2.5}$ is obtained by summing up elemental carbon (EC) and other non-refractory aerosol components measured by the OC/EC analyzer and the CV-ToF-ACSM (Table 1), respectively.

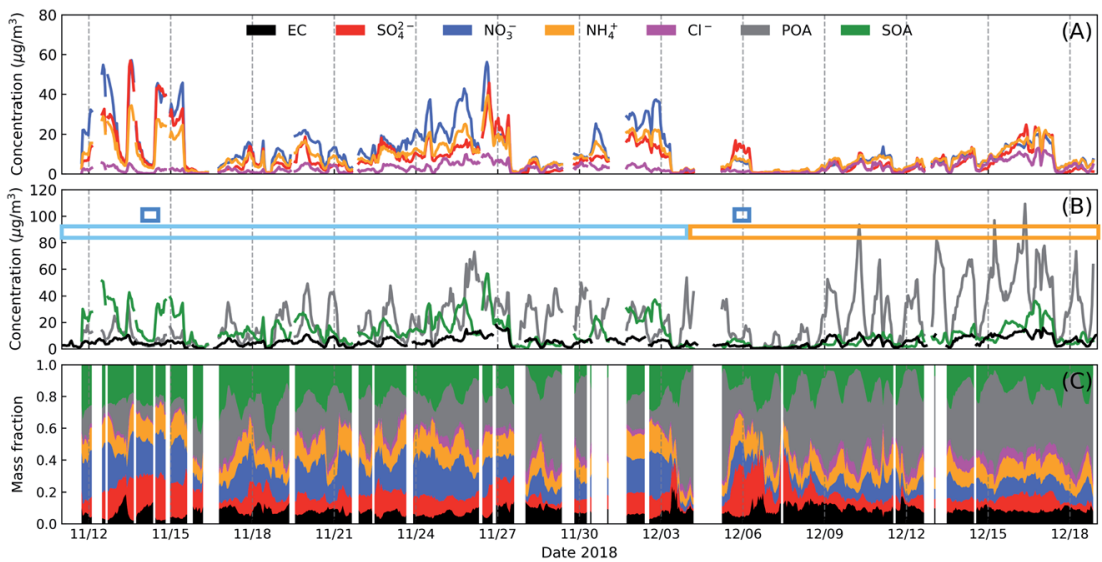

Fig. 2 Time series of submicron aerosol $\left(P M_{1}\right)$ mass concentrations $(A$ and $B)$ and mass fractions of different components $(C)$. In panel $(B)$, the colored rectangles have the same meaning as in Fig. 1. Positive matrix factorization analysis is employed to classify organic aerosol (OA) into various primary OA (POA) factors including hydrocarbon-like OA (HOA), cook-related OA (COA), biomass burning OA (BBOA) and coal combustion OA (CCOA), and a secondary OA (SOA) factor: oxygenated OA (OOA). More details can be found in Fig. 5 and in the work of Sun et al. ${ }^{19}$

chemical compositions of submicron particles $\left(\mathrm{PM}_{1}\right)$. The mean mass concentration of $\mathrm{PM}_{1}$ was $\sim 67 \mu \mathrm{g} \mathrm{m} \mathrm{m}^{-3}$ with a maximum of $\sim 250 \mu \mathrm{g} \mathrm{m} \mathrm{m}^{-3}$. In the low humidity period, the averaged contributions of inorganic components (mainly as 
nitrate, sulfate and ammonium) and organics were $34 \%$ and $57 \%$, respectively. While in the high humidity period, the contribution of inorganics increased to $50 \%$, slightly higher than that of the organic aerosols (43\%). During fog periods, the averaged mass fraction of inorganics reached 59\% and the contribution of organics dropped to $34 \%$. Among organics, the mass fraction of secondary organic aerosols (SOA) in total organic aerosols (ACSM-determined) increased from $23 \%$ in the low humidity period to $47 \%$ and $53 \%$ in high humidity and fog episodes, respectively.

\section{Impact of multiphase processes on aerosol composition and acidity}

\subsection{Aerosol chemical composition}

Ambient RH strongly influences the reaction pathways and their magnitude. ${ }^{20,21}$ Under high RH conditions (e.g., during fog and haze episodes), aerosols tend to become liquid with increased surface and volume concentrations due to hygroscopic growth while under low RH aerosols become solid or semi-solid particles. Thus, we first compared the aerosol composition between different RH conditions. Fig. 3 shows the diel variation of the composition of $\mathrm{PM}_{1}$ between three cases (as marked in Fig. 1 and 2): low humidity ( $\mathrm{RH}=23-69 \%)$, high humidity $(\mathrm{RH}=45-89 \%)$ and fog $(\mathrm{RH}=100 \%)$ along with the averages of the entire campaign period. For the entire campaign (Fig. 3I), $\mathrm{PM}_{1}$ was on average composed of $\sim 9 \%$ elemental carbon (EC), $\sim 11 \%$ sulfate, $\sim 20 \%$ nitrate, $\sim 15 \%$ ammonium, $\sim 3 \%$ chloride, $\sim 15 \%$ POA and $\sim 27 \%$ SOA. The inorganic mass fraction substantially increased from low humidity to high humidity and to the fog case, and SOA also showed a similar but lesser increasing trend even with a decreasing contribution of the total OA. Such phenomenon suggests enhanced formation of secondary species with increasing $\mathrm{RH}$, potentially due to the multiphase processes. ${ }^{22}$ Interestingly, while the mass fraction of sulfate follows the order of low humidity $<$ high humidity $<$ fog periods, for nitrate the order is low humidity $<$
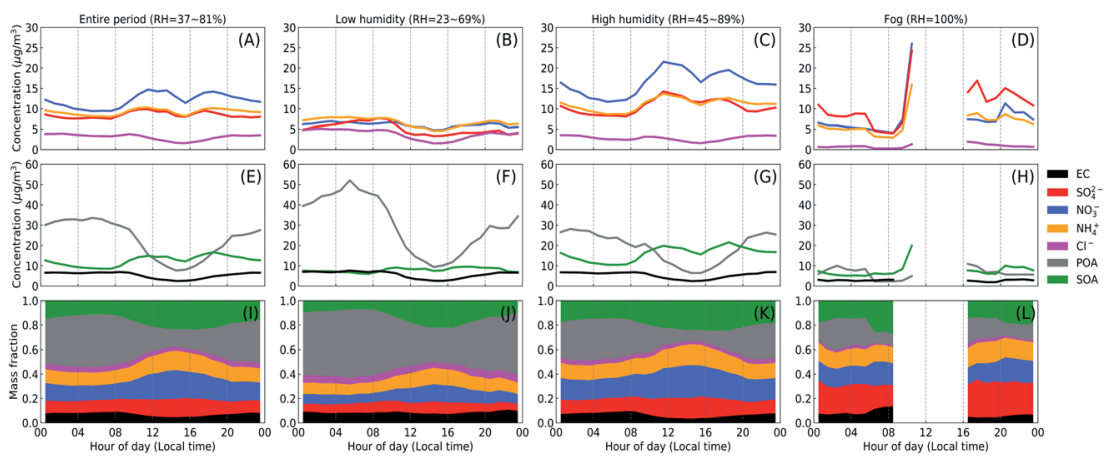

Fig. 3 Diel variations of the submicron aerosol $\left(P M_{1}\right)$ mass concentrations $(A-H)$ and mass fractions $(I-L)$ of the major components of submicron aerosols $\left(P M_{1}\right)$ averaged over the entire campaign and focus periods with different relative humidity $(\mathrm{RH})$ conditions. The solid lines in $(\mathrm{A}-\mathrm{H})$ show the mean value of hourly averaged concentrations of each component. The displayed $\mathrm{RH}$ range relevant to each focus period is based on daily averaged data. 
fog $<$ high humidity (Fig. 3I-L). A clear RH effect is also found on NOR and SOR (molar ratio of nitrate or sulfate to the sum of nitrate and $\mathrm{NO}_{2}$ or sulfate and $\mathrm{SO}_{2}$ ), which represents the degree of secondary formation of nitrate and sulfate. ${ }^{2,23}$ As shown in Fig. 4, the variations of SOR and NOR follow the same trend as the mass fraction of sulfate and nitrate. These results indicate an important role of high RH in promoting the formation of SIA and SOA, probably through multiphase reactions. Information of gases $\left(\mathrm{SO}_{2}, \mathrm{NO}_{2}, \mathrm{NH}_{3}, \mathrm{O}_{3}\right.$ and VOCs) and $\mathrm{PM}_{2.5}$ concentrations can be found in the ESI. $\dagger$

\subsection{Size dependence of aerosol chemical composition}

Sun et al. ${ }^{19}$ characterized aerosol composition and sources of organic aerosol (OA) during the McFAN campaign in 2018, and also the compositional differences between $\mathrm{PM}_{1}$ and $\mathrm{PM}_{2.5}$ by using the CV-ToF-ACSM (Table 1). As depicted in Fig. 5, comparable contributions of $\mathrm{OA}$ and secondary inorganic aerosol (SIA) were found during the high humidity period ( $\mathrm{RH}=73 \pm 24 \%$ ), while the low humidity period ( $\mathrm{RH}=48 \pm 18 \%$ ) showed a reduced contribution of SIA. OA composition was also substantially different with a much higher contribution of secondary OA (46-47\%) during the high humidity period than the low humidity phase (19$21 \%$ ). In contrast, primary OA from biomass burning, coal combustion, and traffic emissions dominated OA (71-73\%) during the low humidity period (Fig. 5B). These results highlight that meteorological conditions, in particular RH, play an important role in secondary aerosol formation in NCP, and hence change the contributions of primary and secondary aerosol.

Sun et al. ${ }^{19}$ further analyzed the chemical differences between $\mathrm{PM}_{1}$ and $\mathrm{PM}_{2.5}$ during both high and low humidity periods. As indicated in Fig. 5, aerosol composition and $\mathrm{OA}$ composition of $\mathrm{PM}_{1}$ and $\mathrm{PM}_{2.5}$ were relatively similar during both focus periods, despite the concentration differences by up to $30 \%$. However, the decreases in $\mathrm{PM}_{1} / \mathrm{PM}_{2.5}$ ratios as a function of $\mathrm{RH}$ were also observed for secondary organic and inorganic aerosol species, which was likely due to the changes in aerosol hygroscopicity and phase states. In contrast, primary aerosol

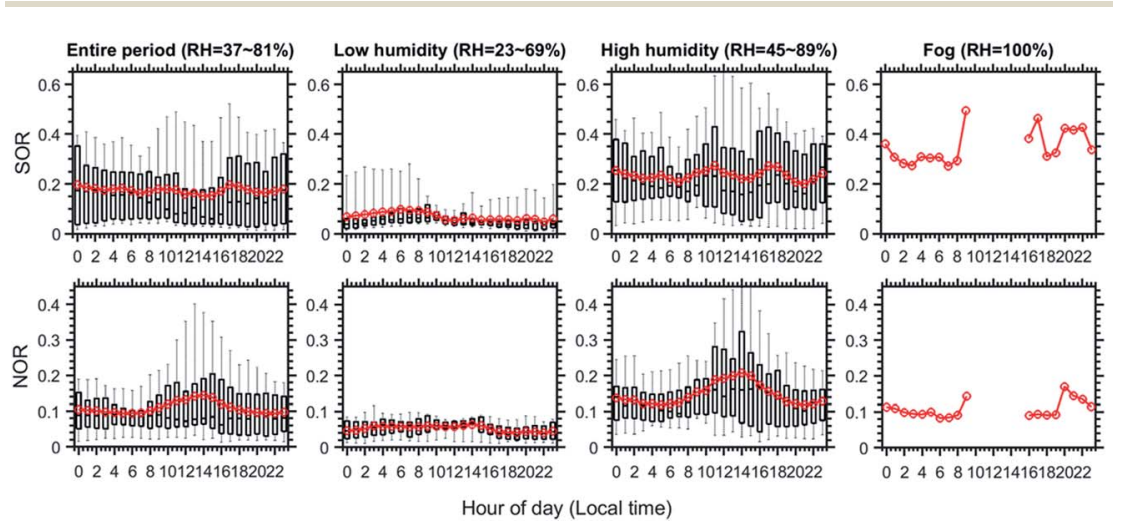

Fig. 4 Diel variations of the ratios of nitrate to nitrate plus $\mathrm{NO}_{2}$ (NOR) and sulfate to sulfate plus $\mathrm{SO}_{2}(\mathrm{SOR})$ averaged over the entire campaign and focus periods with different relative humidity $(\mathrm{RH})$ conditions. The boxes and whiskers indicate percentiles (90th, 75th, 50th (median), 25th and 10th). 

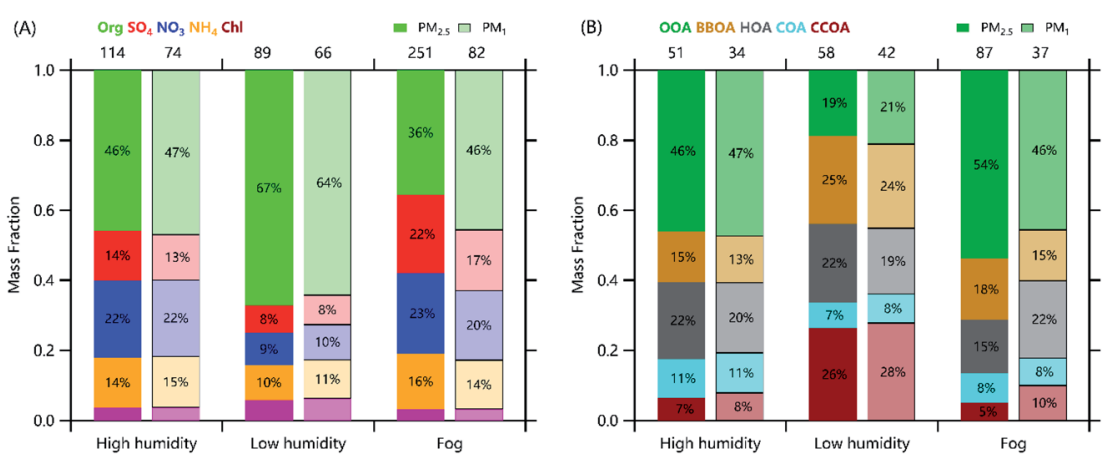

Fig. 5 Average (A) chemical composition of non-refractory $P M_{2.5}$ and $P M_{1}$, and (B) $O A$ composition during the focus periods with different relative humidity $(\mathrm{RH})$ conditions. The numbers on the top of the figures are the average mass concentrations $\left(\mu \mathrm{g} \mathrm{m}^{-3}\right)$ for each period. Adopted and modified from Sun et al. ${ }^{19}$

species with low hygroscopicity did not show clear RH dependence of $\mathrm{PM}_{1} / \mathrm{PM}_{2.5}$ ratios. Large differences in both mass concentrations and composition were observed during fog events. For instance, $\mathrm{PM}_{1}$ on average accounted for $33 \%$ of $\mathrm{PM}_{2.5}$ due to the rapid hygroscopic growth of aerosol particles under high $\mathrm{RH}$ levels, and $\mathrm{PM}_{2.5}$ showed largely elevated contributions of SIA (61\% vs. 51\%) and SOA (54\% vs. $46 \%$ ) compared with $\mathrm{PM}_{1}$. Further analysis showed that the chemical differences between $\mathrm{PM}_{1}$ and $\mathrm{PM}_{2.5}$ had negligible impacts on predictions of particle acidity, while they could affect aerosol liquid water content by up to $50-70 \%$.

\subsection{Aerosol acidity}

To examine aerosol acidity during the campaign, we modelled the aerosol $\mathrm{pH}$ based on the ISORROPIA mode ${ }^{24}$ and observation data. The concentrations of sulfate, nitrate, ammonium and chloride were taken from the CV-ToF-ACSM measurement, and the ammonia concentrations were taken from observations using the Picarro G2103 gas analyzer. Only the data points with $\mathrm{RH}>40 \%$ are used here. Sensitivity studies show that the uncertainty in chloride measurements by the ACSM is expected to result in a $\mathrm{pH}$ variation of -0.15 to 0.35 , while the missing measurements of non-volatile species (i.e., $\mathrm{Na}^{+}, \mathrm{Ca}^{2+}, \mathrm{K}^{+}$and $\mathrm{Mg}^{2+}$ ) are expected to result in a $\mathrm{pH}$ underestimation of 0.07 to 0.35 . In general, simulated gas-particle partitioning of ammonia agrees well with the observations. As shown in Fig. 6, the aerosol $\mathrm{pH}$ averaged $5.1 \pm 0.9$ over the whole observation period. A clear diel variation is observed for the entire and high humidity periods, with an obvious drop in $\mathrm{pH}$ during the daytime, and bottomed around 15:00. This $\mathrm{pH}$ drop is mainly driven by the diel variation in $\mathrm{RH}$ and therefore the aerosol water content (AWC) concentrations. ${ }^{25}$ The diel variation is not complete for low humidity and fog periods, as there is no available afternoon data. The absence of afternoon data during the low humidity period is due to its low $\mathrm{RH}(<40 \%)$ and the aerosols were mostly dry. Similarly, due to stronger solar radiation and lower RH, no foggy events appeared during the afternoons. For these two periods, the nighttime $\mathrm{pH}$ was relatively stable, both of which fluctuating around 5.5. A more 

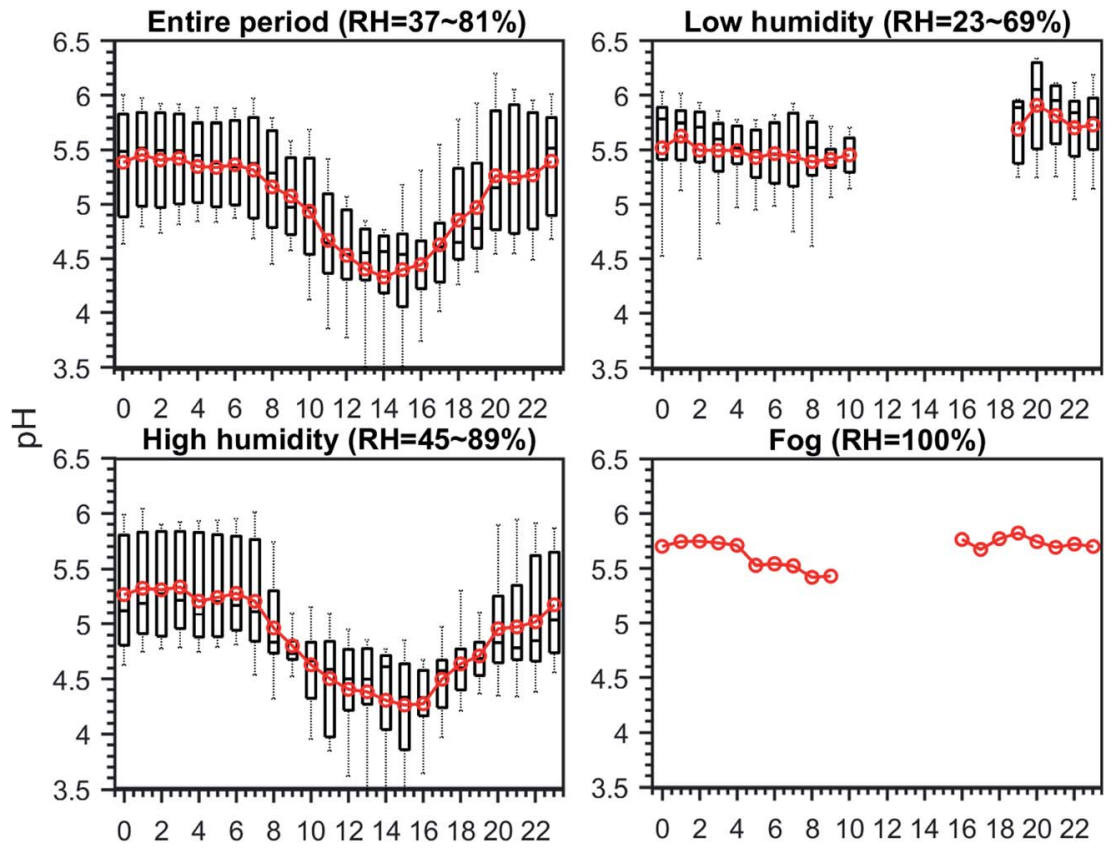

Hour of day (Local time)

Fig. 6 Diel variation of aerosol $\mathrm{pH}$ averaged over the entire campaign and focus periods with different relative humidity $(\mathrm{RH})$ conditions. The boxes and whiskers indicate percentiles (90th, 75th, 50th (median), 25th and 10th), and the red circles represent arithmetic mean values. Note that the displayed $\mathrm{RH}$ ranges for each focus period represent daily averages. Due to limited data points at each hour, only mean values are shown for the fog period.

detailed analysis on the drivers of aerosol $\mathrm{pH}$ can be found elsewhere (Zheng et al., Drivers of aerosol pH during the multiphase chemistry experiment in fogs and aerosols (McFAN) experiment in the North China Plain, in preparation).

\section{Impact of multiphase processes on aerosol physical properties}

\subsection{Aerosol hygroscopicity and phase state}

Fig. 7 shows the diel variations of the measured cloud condensation nuclei (CCN) number concentration at two different supersaturation (SS) levels, under the three cases. For the entire period, $N_{\mathrm{CCN}}$ was lower during daytime ( 09:00-20:00) than at night and this difference became more pronounced at the higher SS value. Similar phenomenon has been reported in another study at the same site during winter time. ${ }^{26}$ At larger SS values, particle size tends to be more crucial in affecting $N_{\mathrm{CCN} .}{ }^{27}$ The lower $N_{\mathrm{CCN}}$ during daytime was likely caused by the varied particle number size distribution (see Fig. S8 $\dagger$ ) and the decreased particle number concentration (see Fig. 8A-D). Compared to the low humidity case, $N_{\mathrm{CCN}}$ in the high humidity case was slightly higher at the lower SS value, which might be due to (1) the larger mass fraction of SIA (nitrate, sulfate and ammonium) and SOA 


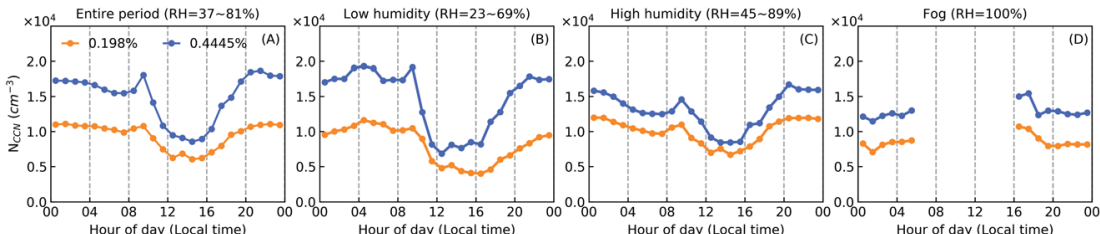

Fig. 7 Diel variations of CCN number concentration at two different supersaturation levels averaged over the entire campaign and focus periods with different relative humidity $(\mathrm{RH})$ conditions. The symbols represent the mean value of hourly averaged concentrations.
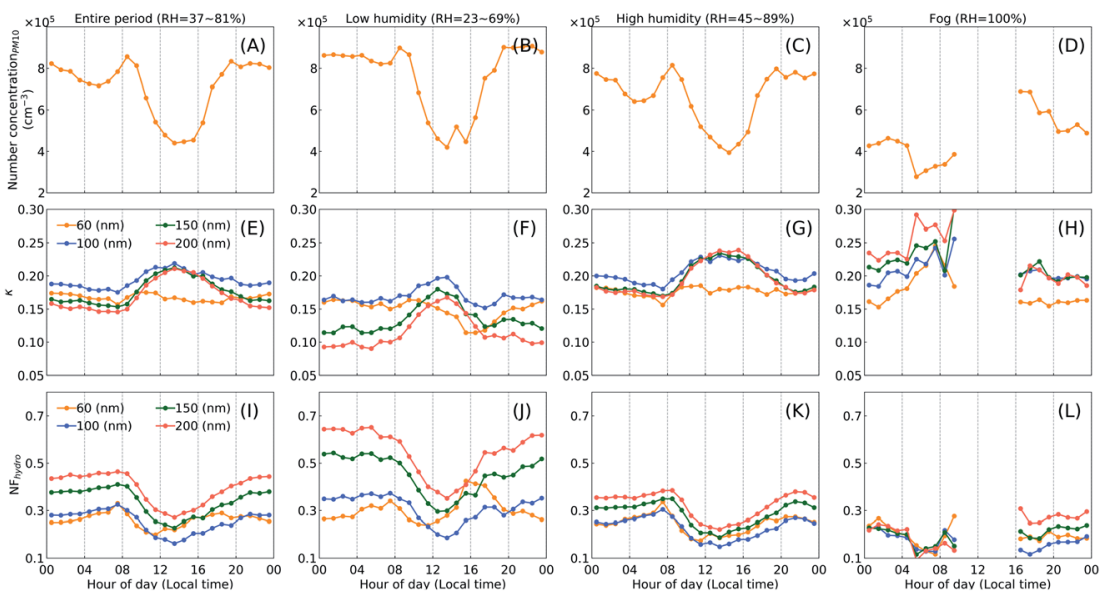

Fig. 8 Diel variations of particle number concentration in $\mathrm{PM}_{10}$ size range (top row), hygroscopicity parameter $\kappa$ (second row) and number fraction of hydrophobic particles $\mathrm{NF}_{\text {hydro }}$ for selected particle sizes (bottom row) averaged over the entire campaign and focus periods with different relative humidity $(\mathrm{RH})$ conditions.

found for the high humidity case in Fig. 3; (2) the increased concentration of larger-size particles under high $\mathrm{RH}$. Increasing the fraction of hydrophilic inorganics and organics in aerosols will enhance their ability to activate into CCN, leading to a higher $N_{\mathrm{CCN}}$. However, for the fog period, $N_{\mathrm{CCN}}$ was even lower than that of the low humidity case. Since fog droplets can efficiently scavenge particles with smaller sizes, the observed particle number concentration within fog events was much lower than during non-fog periods (Fig. 8). Thus, the low aerosol number concentration during fog events might result in the much less $N_{\mathrm{CCN}}$.

The hygroscopicity parameter $\kappa$ (ref. 28 and 29) showed higher values in daytime than at night (Fig. 8E-G), indicating the potential effect of photochemistry in enhancing particles' hygroscopicity. Based on hygroscopicity and aerosol composition measurements during the McFAN campaign, Kuang et al. ${ }^{17}$ found that the hygroscopicity parameter of organic aerosols, $\kappa_{\mathrm{OA}}$, showed a prominent diel variation with a peak value present near 14:30 local time. And this diel variation was highly and positively correlated with the mass fraction of oxygenated organic aerosols (OOA), pointing to the important role of photochemical 
processing in enhancing $\kappa_{\mathrm{OA}}$. Similar photochemical impact was also reported by Wang et $a .^{27}$ at a suburban site in the central NCP. Moreover, an increase of $\kappa$ could be found with increasing ambient $\mathrm{RH}$, i.e., from low humidity to fog case (Fig. $8 \mathrm{~F}-\mathrm{H}$ ). Meanwhile, an opposite trend was observed for $\mathrm{NF}_{\text {hydro, }}$, meaning that the number fraction of hydrophobic particles is getting less. Along with the results shown in Fig. 3, we conclude that the enhanced hygroscopicity of aerosols is due to the increased hydrophilic fraction which is most likely caused by either high-RH favored multiphase reactions or photochemistry, and the coupling of both effects.

\subsection{Aerosol optical properties}

Aerosol optical properties have been found to show a strong $\mathrm{RH}$ dependence, which may result in a positive feedback and influence the planetary boundary layer (PBL) meteorology and the haze formation..$^{30-32}$ Fig. 9 shows the optical properties of aerosols under the three cases. The diel variation of the Absorption Ångström Exponent (AAE) showed higher values during nighttime than during daytime with a much higher $\mathrm{AAE}_{370-470}$ (average \pm std, $1.8 \pm 0.35$ ) than $\mathrm{AAE}_{880-950}$ $(0.8 \pm 0.1)$ (Fig. S9†). This implies that, besides black carbon (BC), there existed some brown carbon $(\mathrm{BrC})$, which had comparable light-absorbing capacities as $\mathrm{BC}$ at short wavelengths. Thus, the feature of higher nighttime $\mathrm{AAE}_{370-950}$ in Fig. 9A-C might be due to increased levels of BrC generated by domestic heating and biomass burning during the night. Significant differences among different RH cases can be found for AAE and the Single Scattering Albedo (SSA). With increased RH from the low humidity to the high humidity case, AAE decreased from $\sim 1.7$ to $\sim 1.55$ and even down to $\sim 1.4$ under fog conditions. The decreased AAE suggests that the fraction of light-absorbing components such as $\mathrm{BC}$ and $\mathrm{BrC}$ is reduced, due to either decreased mass fraction or changed mixing state. ${ }^{33,34}$ For the SSA, however, its values under high humidity were remarkably higher than at low humidity, indicating an enhanced fraction of light-scattering components. This phenomenon could be due to the boosted formation of SIA (i.e., nitrate,
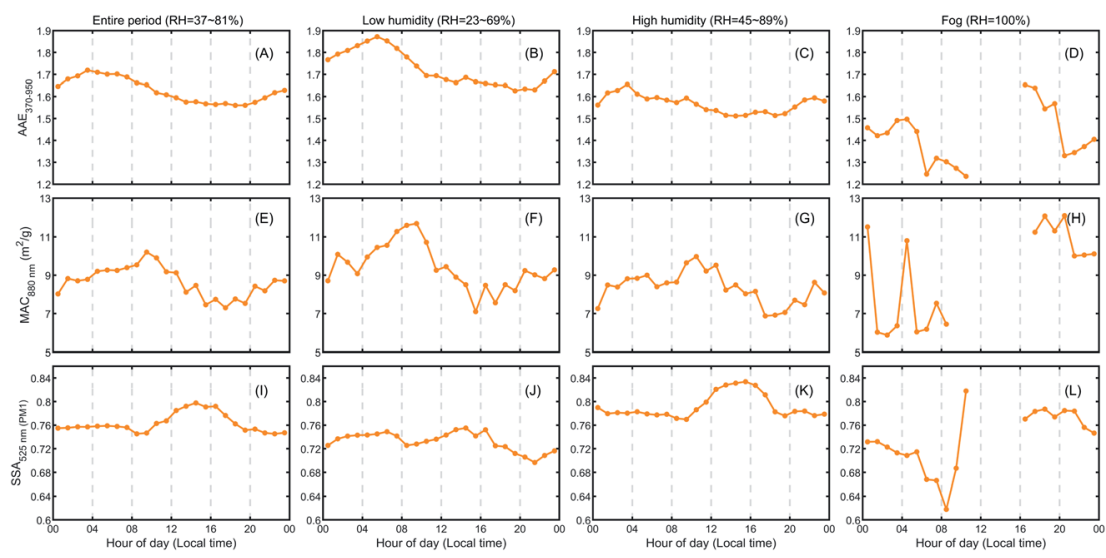

Fig. 9 Diel variations of Absorption Ångström Exponent (top row), Mass Absorption Cross section (second row), and Single Scattering Albedo (bottom row) averaged over the entire campaign and focus periods with different relative humidity $(\mathrm{RH})$ conditions. 
sulfate and ammonium) and SOA through high-RH-favored multiphase reactions, as shown in Fig. 3. For example, Lim et al. ${ }^{35}$ have reported the important role of sulfate in East Asia: it could enhance SSA and also alter the absorption properties of aerosols. Moreover, in Fig. 9K, the more prominent enhancement of SSA during daytime correlates well with the enhanced formation of nitrate and SOA under the influence of solar radiation (Fig. 3K). A recent study at the same site by Kuang et $a{ }^{22}$ has revealed that rapid OOA formation could be induced by photochemical aqueous-phase reactions. The RH effect on the Mass Absorption Cross-section (MAC), however, was negligible, and further investigations on the underlying mechanisms may be needed.

\section{Summary}

In this work, we present an overview of the preliminary results obtained from an intensive winter campaign in 2018 in the North China Plain, during the McFAN experiment. The McFAN experiment aimed at exploring the underlying mechanisms of haze formation and evolution, especially focusing on the effect of multiphase chemistry. The ambient RH conditions during the 45-day campaign were separated into two stages, with the first stage staying at a relatively high $\mathrm{RH}$ range (daily averages about 45-89\%) and the second at a low $\mathrm{RH}$ level (daily averages about $23-69 \%)$. Two typical fog events $(\mathrm{RH}=100 \%)$ during the observation period were captured additionally. Thus, to better elucidate the potential influence of multiphase processes, we generally present and discuss the measurement results in terms of three characteristic periods: low humidity, high humidity and fog.

The aerosol composition and $\mathrm{OA}$ composition of $\mathrm{PM}_{1}$ and $\mathrm{PM}_{2.5}$ were relatively similar during both low and high humidity periods. However, compared with the low $\mathrm{RH}$ period, both $\mathrm{PM}_{1}$ and $\mathrm{PM}_{2.5}$ showed increased mass fraction of SIA (nitrate, sulfate and ammonium) and SOA during high RH and fog episodes. The enhanced contribution of SIA and SOA was most likely caused by aqueous-phase reactions favored by high $\mathrm{RH}$. Moreover, the rapid growth of nitrate and SOA during daytime highlighted the important role of photochemical reactions.

The change in aerosol composition could drive variations in multiple aerosol physicochemical properties. For example, the increased $\kappa$ at high $\mathrm{RH}$ reflected the more hydrophilic feature of aerosols, likely due to the increased fraction of hydrophilic SIA and SOA. The calculated aerosol pH displayed a significant diel variation, with lower $\mathrm{pH}$ during daytime than at nighttime. Diel variations were also found for aerosol optical properties such as AAE and SSA, but with opposite trends between the two parameters. The variations found for these parameters were most likely driven by varied ambient $\mathrm{RH}$ and thereby the changed aerosol composition affected by multiphase processes.

\section{Author contributions}

H.S. and Y.C. conceived and designed this study. H.S., Y.C. and N.M. organized the campaign. N.M., G.L., Y.S., Y.G. and G.Z. contributed to data analyses, plots and related discussions in the manuscript. S.Z., X.P., N.L. and M.T. helped to make plots and provided suggestions on experiment results discussion. J.T., Y.K., Q.W., J.H., Y.Z., U.K., S.Z., X.P., Z.W., P.C., W.X., G.Z., C.Z., B.Y., M.S., A.D., Q.Z., 
P.F. and Y.S. provided measurement data. G.L. and H.S. wrote the manuscript with inputs from Y.C., G.Z., U.P. and U.K.

\section{Conflicts of interest}

There are no conflicts to declare.

\section{Acknowledgements}

We acknowledge the National Key Research and Development Program of China (grant no. 2017YFC0210104), the National Natural Science Foundation of China (grant no. 91644218) and the support from the Max Planck Society. G. L. acknowledges the financial support from the China Scholarship Council (CSC). Open Access funding provided by the Max Planck Society.

\section{References}

1 Y. Cheng, G. Zheng, C. Wei, Q. Mu, B. Zheng, Z. Wang, M. Gao, Q. Zhang, K. He, G. Carmichael, U. Pöschl and H. Su, Sci. Adv., 2016, 2, e1601530.

2 G. J. Zheng, F. K. Duan, H. Su, Y. L. Ma, Y. Cheng, B. Zheng, Q. Zhang, T. Huang, T. Kimoto, D. Chang, U. Pöschl, Y. F. Cheng and K. B. He, Atmos. Chem. Phys., 2015, 15, 2969-2983.

3 Y. Sun, Q. Jiang, Z. Wang, P. Fu, J. Li, T. Yang and Y. Yin, J. Geophys. Res.: Atmos., 2014, 119, 4380-4398.

4 Y. L. Sun, Z. F. Wang, P. Q. Fu, T. Yang, Q. Jiang, H. B. Dong, J. Li and J. J. Jia, Atmos. Chem. Phys., 2013, 13, 4577-4592.

5 M. Li, Q. Zhang, D. G. Streets, K. B. He, Y. F. Cheng, L. K. Emmons, H. Huo, S. C. Kang, Z. Lu, M. Shao, H. Su, X. Yu and Y. Zhang, Atmos. Chem. Phys., 2014, 14, 5617-5638.

6 M. Li, Q. Zhang, J. I. Kurokawa, J. H. Woo, K. He, Z. Lu, T. Ohara, Y. Song, D. G. Streets, G. R. Carmichael, Y. Cheng, C. Hong, H. Huo, X. Jiang, S. Kang, F. Liu, H. Su and B. Zheng, Atmos. Chem. Phys., 2017, 17, 935-963.

7 R. Zhang, G. Wang, S. Guo, M. L. Zamora, Q. Ying, Y. Lin, W. Wang, M. Hu and Y. Wang, Chem. Rev., 2015, 115, 3803-3855.

8 D. Chen, Z. Liu, J. Fast and J. Ban, Atmos. Chem. Phys., 2016, 16, 10707-10724.

9 G. Wang, R. Zhang, M. E. Gomez, L. Yang, M. Levy Zamora, M. Hu, Y. Lin, J. Peng, S. Guo, J. Meng, J. Li, C. Cheng, T. Hu, Y. Ren, Y. Wang, J. Gao, J. Cao, Z. An, W. Zhou, G. Li, J. Wang, P. Tian, W. Marrero-Ortiz, J. Secrest, Z. Du, J. Zheng, D. Shang, L. Zeng, M. Shao, W. Wang, Y. Huang, Y. Wang, Y. Zhu, Y. Li, J. Hu, B. Pan, L. Cai, Y. Cheng, Y. Ji, F. Zhang, D. Rosenfeld, P. S. Liss, R. A. Duce, C. E. Kolb and M. J. Molina, Proc. Natl. Acad. Sci. U. S. A., 2016, 113, 13630-13635.

10 G. Li, N. Bei, J. Cao, R. Huang, J. Wu, T. Feng, Y. Wang, S. Liu, Q. Zhang, X. Tie and L. T. Molina, Atmos. Chem. Phys., 2017, 17, 3301-3316.

11 J. Shao, Q. Chen, Y. Wang, X. Lu, P. He, Y. Sun, V. Shah, R. V. Martin, S. Philip, S. Song, Y. Zhao, Z. Xie, L. Zhang and B. Alexander, Atmos. Chem. Phys., 2019, 19, 6107-6123.

12 T. Chen, B. Chu, Y. Ge, S. Zhang, Q. Ma, H. He and S.-M. Li, Environ. Pollut., 2019, 252, 236-244. 
13 M. Gen, R. Zhang, D. D. Huang, Y. Li and C. K. Chan, Environ. Sci. Technol., 2019, 53, 8757-8766.

14 J. Wu, N. Bei, B. Hu, S. Liu, M. Zhou, Q. Wang, X. Li, L. Liu, T. Feng, Z. Liu, Y. Wang, J. Cao, X. Tie, J. Wang, L. T. Molina and G. Li, Atmos. Chem. Phys., 2019, 19, 8721-8739.

15 J. Xue, X. Yu, Z. Yuan, S. M. Griffith, A. K. H. Lau, J. H. Seinfeld and J. Z. Yu, Nat. Geosci., 2019, 12, 977-982.

16 W. Tao, H. Su, G. Zheng, J. Wang, C. Wei, L. Liu, N. Ma, M. Li, Q. Zhang, U. Pöschl and Y. Cheng, Atmos. Chem. Phys. Discuss., 2020, 2020, 1-31.

17 Y. Kuang, Y. He, W. Xu, P. Zhao, Y. Cheng, G. Zhao, J. Tao, N. Ma, H. Su, Y. Zhang, J. Sun, P. Cheng, W. Yang, S. Zhang, C. Wu, Y. Sun and C. Zhao, Atmos. Chem. Phys., 2020, 20, 865-880.

18 W. Xu, Y. Kuang, C. Zhao, J. Tao, G. Zhao, Y. Bian, W. Yang, Y. Yu, C. Shen, L. Liang, G. Zhang, W. Lin and X. Xu, Atmos. Chem. Phys., 2019, 19, 1055710570.

19 Y. Sun, Y. He, Y. Kuang, W. Xu, S. Song, N. Ma, J. Tao, P. Cheng, C. Wu, H. Su, Y. Cheng, C. Xie, C. Chen, L. Lei, Y. Qiu, P. Fu, P. Croteau and D. R. Worsnop, Geophys. Res. Lett., 2020, 47, e2019GL086288.

20 A. R. Ravishankara, Science, 1997, 276, 1058-1065.

21 H. Su, Y. Cheng and U. Pöschl, Acc. Chem. Res., 53, 2034-2043.

22 Y. Kuang, Y. He, W. Xu, B. Yuan, G. Zhang, Z. Ma, C. Wu, C. Wang, S. Wang, S. Zhang, J. Tao, N. Ma, H. Su, Y. Cheng, M. Shao and Y. Sun, Environ. Sci. Technol., 2020, 54(7), 3849-3860.

23 Y. Sun, G. Zhuang, A. Tang, Y. Wang and Z. An, Environ. Sci. Technol., 2006, 40, 3148-3155.

24 C. Fountoukis and A. Nenes, Atmos. Chem. Phys., 2007, 7, 4639-4659.

25 G. Zheng, H. Su, S. Wang, M. O. Andreae, U. Pöschl and Y. Cheng, Science, 2020, 369, 1374-1377.

26 Y. Zhang, J. Tao, N. Ma, Y. Kuang, Z. Wang, P. Cheng, W. Xu, W. Yang, S. Zhang, C. Xiong, W. Dong, L. Xie, Y. Sun, P. Fu, G. Zhou, Y. Cheng and H. Su, Sci. Total Environ., 2020, 719, 137473.

27 Y. Wang, Z. Li, Y. Zhang, W. Du, F. Zhang, H. Tan, H. Xu, T. Fan, X. Jin, X. Fan, Z. Dong, Q. Wang and Y. Sun, Atmos. Chem. Phys., 2018, 18, 11739-11752.

28 S. M. Kreidenweis, K. Koehler, P. J. DeMott, A. J. Prenni, C. Carrico and B. Ervens, Atmos. Chem. Phys., 2005, 5, 1357-1370.

29 H. Su, D. Rose, Y. F. Cheng, S. S. Gunthe, A. Massling, M. Stock, A. Wiedensohler, M. O. Andreae and U. Pöschl, Atmos. Chem. Phys., 2010, 10, 7489-7503.

30 Y. F. Cheng, A. Wiedensohler, H. Eichler, J. Heintzenberg, M. Tesche, A. Ansmann, M. Wendisch, H. Su, D. Althausen, H. Herrmann, T. Gnauk, E. Brüggemann, M. Hu and Y. H. Zhang, Atmos. Environ., 2008, 42, 6373-6397.

31 A. J. Ding, X. Huang, W. Nie, J. N. Sun, V.-M. Kerminen, T. Petäjä, H. Su, Y. F. Cheng, X.-Q. Yang, M. H. Wang, X. G. Chi, J. P. Wang, A. Virkkula, W. D. Guo, J. Yuan, S. Y. Wang, R. J. Zhang, Y. F. Wu, Y. Song, T. Zhu, S. Zilitinkevich, M. Kulmala and C. B. Fu, Geophys. Res. Lett., 2016, 43, 28732879.

32 X. Tie, R.-J. Huang, J. Cao, Q. Zhang, Y. Cheng, H. Su, D. Chang, U. Pöschl, T. Hoffmann, U. Dusek, G. Li, D. R. Worsnop and C. D. O'Dowd, Sci. Rep., 2017, 7, 15760. 
33 Y. F. Cheng, M. Berghof, R. M. Garland, A. Wiedensohler, B. Wehner, T. Müller, H. Su, Y. H. Zhang, P. Achtert, A. Nowak, U. Pöschl, T. Zhu, M. Hu and L. M. Zeng, J. Geophys. Res.: Atmos., 2009, 114, D00G10.

34 Y. F. Cheng, H. Eichler, A. Wiedensohler, J. Heintzenberg, Y. H. Zhang, M. Hu, H. Herrmann, L. M. Zeng, S. Liu, T. Gnauk, E. Brüggemann and L. Y. He, J. Geophys. Res.: Atmos., 2006, 111, D20204.

35 S. Lim, M. Lee, S.-W. Kim and P. Laj, Sci. Rep., 2018, 8, 5172. 